\title{
Conservative Treatment for Locally Advanced Carcinoma of the Larynx Using Alpha-Crystalline B as a Prognostic Molecular Marker
}

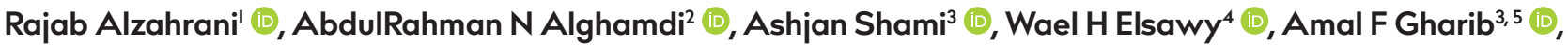 \\ Hanan S. Amin ${ }^{6}$ (D, Majed AlMourgi ${ }^{7}$ (1)
}

'Department of Surgery, Otolaryngology Division, Medical College, Al Baha University, Al Baha, Saudi Arabia

${ }^{2}$ Department of Family Medicine, Medical College, Taif University, Taif, Saudi Arabia

${ }^{3}$ Department of Clinical Laboratory Sciences, College of Applied Medical Sciences, Taif University, Taif, Saudi Arabia

${ }^{4}$ Department of Clinical Oncology, Faculty of Medicine, Zagazig University, Zagazig, Egypt

${ }^{5}$ Department of Medical Biochemistry, Faculty of Medicine, Zagazig University, Zagazig, Egypt

${ }^{6}$ Department of Clinical Chemistry, Theodor Bilharz Research Institute, Cairo, Egypt

${ }^{7}$ Department of Surgery, Medical College, Taif University, Taif, Saudi Arabia

ORCID iDs of the authors: R.A. 0000-0002-54II-0454; A.N.A. 0000-0003-4593-4846; A.S. 0000-0003-0456-552x; W.H.E. 0000-00034938-6883; A.F.G. 0000-000I-8008-3368; H.S.A. 0000-0002-6573-8570; M.A. 0000-0002-3080-5083.

Cite this article as: Alzahrani R, Alghamdi AN, Shami A, Elsawy WH, Gharib AF, Amin HS, et al. Conservative Treatment for Locally Advanced Carcinoma of the Larynx Using Alpha-Crystalline B as a Prognostic Molecular Marker. Cyprus J Med Sci 2020; 5(4): 317-22.

\section{BACKGROUND/AIMS}

This study was performed to understand the prognostic role of alpha-crystalline $B(a B C)$ in locally advanced laryngeal cancer.

\section{MATERIAL and METHODS}

Forty-five patients were enrolled; they were treated with induction chemotherapy followed by definitive radiotherapy. Alpha-crystalline $\mathrm{B}(\mathrm{aBC})$ was evaluated using quantitative real time-polymerase chain reaction.

\section{RESULTS}

Complete response to induction chemotherapy was observed in 16 patients, and partial response was achieved in 27 patients. After radiation therapy, 32 patients showed complete response. The aBC level was significantly higher in the tumor tissues than in the normal adjacent tissues. This level was significantly correlated with the patient's age, clinical stage, and treatment response. High aBC levels were significantly associated with short overall and disease-free survival.

\section{CONCLUSION}

Induction chemotherapy can efficiently preserve the larynx in a high proportion of patients. aBC can be used as a molecular marker for predicting the treatment response and survival in patients undergoing induction chemotherapy.

Keywords: Locally advanced cancer larynx, induction chemotherapy, aB-crystalline, qRT-PCR, prognostic factors

\section{INTRODUCTION}

Total laryngectomy with cervical lymph nodes dissection accompanied by radiotherapy has been recognized as a suitable treatment for locally advanced laryngeal cancer (I). Patients treated with total laryngectomy experience the following postoperative complications: loss of speaking ability and impaired swallowing, with their impact on the quality of living leading to many social issues (2). The problems arising from total laryngectomy raise the need for the establishment of a novel treatment strategy that has similar treatment efficacy and survival rate, with acceptable complications (3). The concept of preserving the larynx has been approached by various modalities, including chemotherapy to downstage the tumor so that the patient can be treated with less radical surgery or by using radiotherapy. Induction chemotherapy in locally advanced head and neck cancer has been studied during the previous three decades. However, there is no consensus for the optimal use of induction chemotherapy in head and neck malignancies except in locally advanced laryngeal cancer (4). 
The chain of alpha-crystalline $B(a B C)$ is a protein encoded by the CRYAB gene in humans (5). It is part of the family of heat shock proteins and acts as a molecular chaperone that mainly binds misfolded proteins to prevent protein aggregation, inhibiting apoptosis and contributing to the intracellular architecture (5). Defects in this gene/protein have been associated with cancer and neurodegenerative diseases, such as Alzheimer's disease and Parkinson's disease. Alpha-B chain crystalline (aBC) can be triggered by heat shock, ischemia, and oxidation and belongs to the family of heat shock proteins. They behave as molecular chaperones although they do not re-naturalize proteins and release them as a real chaperone; instead, they bind improperly folded proteins to prevent their aggregation (6). In addition, by inhibiting the processing of the pro-apoptotic protein caspase-3, aBC can confer stress resistance to cells. Two unique features of alpha crystallines are autokinase function and intracellular architecture integration (7). Alpha-A and alpha-B gene products are expressed independently; alpha-A is preferentially limited to the lens and retina, while alpha-B is commonly expressed in several tissues and organs (8).

Although significantly expressed in eye lenses and muscle tissues, aBC may also be observed in several cancers, including squamous cell carcinoma in the head and neck (HNSCC) and breast carcinomas $(9,10)$. aBC expression is associated with the metastases in HNSCC and breast carcinomas and other types of cancer; further, its expression is commonly associated with bad prognosis (9-II).

This study aimed to study the expression level of aB-crystalline in locally advanced squamous cell carcinoma of the larynx with normal nearby tissues adjacent to the tumor. We also studied the relationship between its expression and the clinicopathological features.

\section{MATERIAL and METHODS}

From August 2013 to January 2020, 54 patients with locally advanced cancer of the larynx were referred to the Clinical Oncology Department and Head and neck surgical Oncology Unit, Zagazig University Hospitals, Zagazig, Egypt and East Jeddah Hospital, Jeddah, SA were evaluated for this study. The study was performed with the understanding and written consent of each patient and was approved by the Ethics Committee of the Faculty of Medicine, Zagazig University (257/2013).

\section{Eligibility criteria:}

I. No previous treatment

2. Biopsy-proved squamous cell carcinoma of the larynx

3. Locally advanced disease (T3 or T4 with No, NI or N2) as per the American Joint Committee for cancer staging (12)

4. Performance status of $\geq 2$ on the ECOG scale (I3)

\section{Main Points:}

- Induction chemotherapy can be used effectively in locally advanced laryngeal cancer followed by radiotherapy and can be efficient in conserving the larynx in a certain proportion of patients without compromising survival.

- High level of aBC may be correlated with aggressive behavior of SCC of the larynx and unfavorable outcome.
5. Adequate hepato-renal, cardiac, and bone marrow functions 6. Adequate nutritional and auditory status

7. Written informed consent for study participation 8. Age $<70$ y

The initial evaluation included a history and physical examination, complete blood cell count, routine serum chemistries, creatinine clearance test, chest radiography, computed tomography (CT) scan or magnetic resonance imaging (MRI) of the head and neck, and bone scan. Local tumor extent and regional metastases were further assessed using triple endoscopy, and a biopsy was obtained from the tumor tissues and adjacent normal tissues.

\section{Induction Chemotherapy:}

The induction chemotherapy comprised the following three cycles of docetaxel $75 \mathrm{mg} / \mathrm{m}^{2}$ (day I), cisplatin $75 \mathrm{mg} / \mathrm{m}^{2}$ (day I), and a continuous fluorouracil infusion at $500 \mathrm{mg} / \mathrm{m}^{2}$ per day (days $1-5$ ) every 4 wk.

Response to induction chemotherapy was evaluated clinically via endoscopic examination before each cycle and radiologically using CT scan or MRI that was performed after the second cycle. Assessment of palpable lymph node(s) was done also by clinical examination and palpation. Responding patients (Complete response (CR) or PR) received a maximum of three courses of chemotherapy before to definitive radiation. After the third cycle, patients with CR or PR were treated with irradiation while patients with any evidence of disease progression underwent surgical resection and postoperative radiation therapy. Tumor responses were defined as per the Response Evaluation Criteria in Solid Tumors criteria (RECIST) (I4).

\section{Radiation Therapy:}

All patients received radiotherapy, either immediately after chemotherapy in CR or PR patients or postoperatively in patients who failed to respond to chemotherapy. After chemotherapy, comprehensive radiation therapy was delivered with 5000 cGy supplemented by a boost of 2000 cGy to the primary tumor site and persistent lymph nodes, when present. A dose of 5000 cGy was administered after the surgery and a booster dose of $14 \mathrm{~Gy}$ was administered to sites with positive margins and/or extracapsular spread and/or three or more involved lymph nodes, if any. The response was re-evaluated 12 wk after radiation therapy. Patients with persistent laryngeal disease underwent salvage laryngectomy, while those with persistent neck disease and those whose primary tumor was controlled underwent dissection of the neck alone.

\section{Surgery:}

The extent of surgical resection was determined as per the original assessment of the extent of the tumor before chemotherapy. Classic wide-field total laryngectomy was performed for all primary tumors. Regional neck dissections were performed in all surgical patients except those with T3N0 or those with midline supraglottic T4N0 tumors for whom it could not be determined which side of the neck was chiefly at risk of occult metastases. Salvage surgery was performed after the confirmation of residval tumor on biopsy. All the patients were followed up and examined on a 3-month basis for the first year after treatment and every 6 mon thereafter. 
Quantitative real time-polymerase chain reaction:

Total RNA was obtained using a commercial reagent (Trizol, Gibco Inc., Grand Island, NY, USA) from tumor tissues and nearby normal tissues. Using oligo-dT primers and M-MLV reverse transcriptase, total RNA $(2 \mu \mathrm{g})$ was reverse transcribed. RT-PCR products comprising $\mathrm{aB}$-crystalline and $\beta$-actin were amplified using gene a specific primer (aB-crystalline: F- 5'-GGAATTGATCGCCATCCACCAC-3', R- 5'-CCGCTCGAGCTATTTCTTGGGGGCTGCGG-3', $\beta$-actin: F- 5'-GCA CCA CAC CTT CTA CAA TG-3', R- 5'-CTA GAA GCA TTT GCG GTG GAC GAT GGA GGG-3'). A mixture $(40 \mu \mathrm{L})$ of $3 \mu \mathrm{L}$ cDNA, $10 \mu \mathrm{M}$ primers, $2.5 \mu \mathrm{g} / \mathrm{mL}$ Go Tag Flexi DNA polymerase (Promega), $50 \mathrm{mM} \mathrm{KCl}, 10 \mathrm{mM}$ Tris- $\mathrm{HCl}(\mathrm{pH}$, 9.0), $3.0 \mathrm{mM} \mathrm{MgCl} 2$, and $0.2 \mathrm{mM}$ dNTPs, was prepared to perform PCR. In a 9700 Thermocycler (Perkin-Elmer), PCR was performed, and the general thermocycling conditions were as follows: I cycle of initial denaturation at $95^{\circ} \mathrm{C}$ for $2 \mathrm{~min}$, supplemented by $30 \mathrm{cy}$ cles at $95^{\circ} \mathrm{C}$ for $30 \mathrm{~s}$, annealing at $55^{\circ} \mathrm{C}$ for $40 \mathrm{~s}$ and reaction at $72^{\circ} \mathrm{C}$ for $100 \mathrm{~s}$, followed by supplementation by a final extension for about $5 \mathrm{~min}$ at $72^{\circ} \mathrm{C}$. The relative value of aB-Crystalline mRNA was evaluated using the relative cycle threshold (Ct) means (I5).

\section{Statistical Analysis}

Statistical analyses were performed using the Statistical Package for Social Sciences software version 12.0 (SPSS Inc.; Chicago, IL, USA). Student's t-test and one-way analysis of variance (ANOVA) test were used to compare the mean \pm standard deviation (SD) values of the aB-crystalline expression levels of the different groups. Kaplan Meier survival curves were used to compare the overall and disease-free survival of the groups.

\section{RESULTS}

The study involved 54 patients, including 45 men and 9 women. The median patient age was 51 y (range 40-62 y). After 2 cycles

\begin{tabular}{|lcc|}
\hline $\begin{array}{l}\text { TABLE I. Clinical response of patients after induction } \\
\text { and I2 wk after radiotherapy }\end{array}$ & $\begin{array}{c}\text { Response after } \\
\text { chemotherapy }\end{array}$ & $\begin{array}{c}\text { Response after } \\
\text { Radiotherapy }\end{array}$ \\
\hline Number of patients & 54 & 43 \\
Complete response (\%) & $16(29.6)$ & 32 \\
Partial response (\%) & $27(50)$ & 9 \\
Stable disease (\%) & II (20.4) & 2 \\
\hline
\end{tabular}

\begin{tabular}{|c|c|c|c|}
\hline & & \multicolumn{2}{|c|}{$\begin{array}{l}\text { Surgical salvage after } \\
\text { neoadjuvant chemotherapy }(n=I I)\end{array}$} \\
\hline & & $\begin{array}{l}\text { Unilateral regional } \\
\text { neck dissection }\end{array}$ & $\begin{array}{l}\text { Bilateral regional } \\
\text { neck dissection }\end{array}$ \\
\hline \multicolumn{4}{|l|}{$\begin{array}{l}\text { Total laryngectomy with } \\
\text { partial pharengectomy }\end{array}$} \\
\hline Total laryngectomy & 5 & 3 & 2 \\
\hline Hemi laryngectomy & 4 & 4 & - \\
\hline \multicolumn{4}{|c|}{ Surgical salvage after chemotherapy and radiation therapy $(n=I I)$} \\
\hline Total laryngectomy & - & - & - \\
\hline Hemi laryngectomy & 4 & । & 3 \\
\hline Neck dissection only & 7 & 5 & 2 \\
\hline
\end{tabular}

of induction chemotherapy, complete clinical response was noted in 16 patients. Partial response was achieved by 27 patients. After 3 cycles of chemotherapy, 43 patients received radiation therapy. In 32 patients (32/43), CR was noted (Table I). Salvage surgery was performed after chemotherapy in II patients and II patients with residual disease after chemotherapy and radiotherapy (9 PR and 2 SD) (Table 2).

\section{$\alpha B C$ levels in SCC of the larynx and their nearby normal tissues}

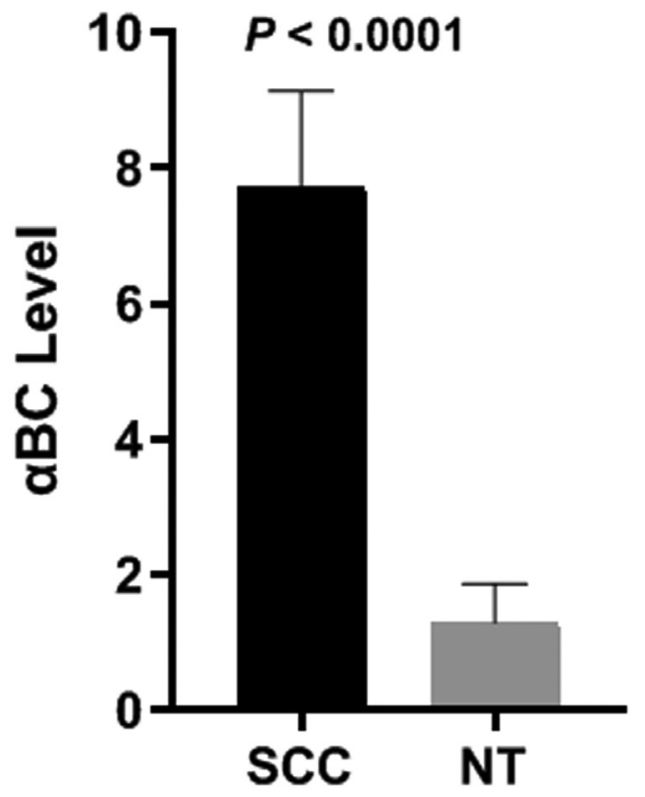

FIGURE I. aBC levels in laryngeal cancer tissues (SCC) and their nearby normal tissues (NAT)

\section{$\alpha B C$ levels and tumor stage}

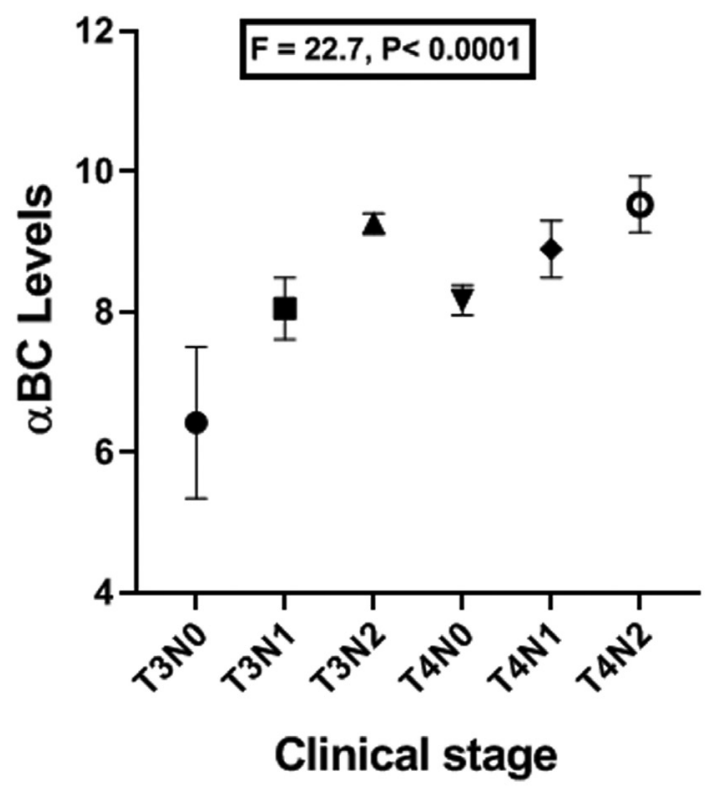

FIGURE 2. Levels of aBC as per the tumor stage 
After chemotherapy and radiotherapy, all the patients with PR had $C R$ in the primary site without $C R$ in cervical lymph nodes; five patients underwent regional neck dissection, and two patients underwent modified radical neck dissection.

The aB-crystalline expression level was assessed in squamous cell carcinoma (SCC) of the larynx relative to the nearby normal tissues adjacent to the tumor. In SCC, the aBC level ranged from

\begin{tabular}{|c|c|c|c|c|c|}
\hline \multirow{2}{*}{$\begin{array}{l}\text { Patients characteristics } \\
\text { Age }\end{array}$} & \multicolumn{3}{|c|}{ aB-crystalline } & \multirow[b]{2}{*}{ t-test } & \multirow[b]{2}{*}{$\mathbf{P}$} \\
\hline & No & Mean & SD & & \\
\hline$<50$ years & 19 & 5.2 & I & & \\
\hline$\geq 50$ years & 35 & 6.6 & 1.7 & 3.16 & 0.003 \\
\hline \multicolumn{6}{|l|}{ Sex } \\
\hline Male & 45 & 6.89 & 0.99 & & \\
\hline Female & 9 & 6.61 & 1.24 & 0.73 & 0.47 \\
\hline \multicolumn{6}{|l|}{$\mathrm{T}$} \\
\hline T2 & 8 & 5.64 & 1.37 & & \\
\hline T3 & 33 & 7.80 & 1.08 & & \\
\hline T4 & 13 & 8.82 & 0.61 & $23.47^{* *}$ & $<0.0001$ \\
\hline \multicolumn{6}{|l|}{$\mathbf{N}$} \\
\hline NO & 12 & 7.01 & 1.22 & & \\
\hline $\mathrm{NI}$ & 27 & 8.24 & 0.56 & & \\
\hline N2 & 15 & 7.39 & 2.16 & $4.24^{* *}$ & 0.0198 \\
\hline \multicolumn{6}{|l|}{ Stage } \\
\hline III & 33 & 6.26 & 0.59 & & \\
\hline IVA & 21 & 7.76 & 0.89 & 7.44 & $<0.0001$ \\
\hline \multicolumn{6}{|c|}{ Response to treatment as per the pretreatment $\mathrm{aBC}$ levels } \\
\hline Complete response (CR) & 32 & 6.12 & 0.45 & & \\
\hline $\begin{array}{l}\text { Partial response or stable } \\
\text { disease (PR/SD) }\end{array}$ & II & 7.35 & 0.32 & 8.42 & $<0.0001$ \\
\hline
\end{tabular}

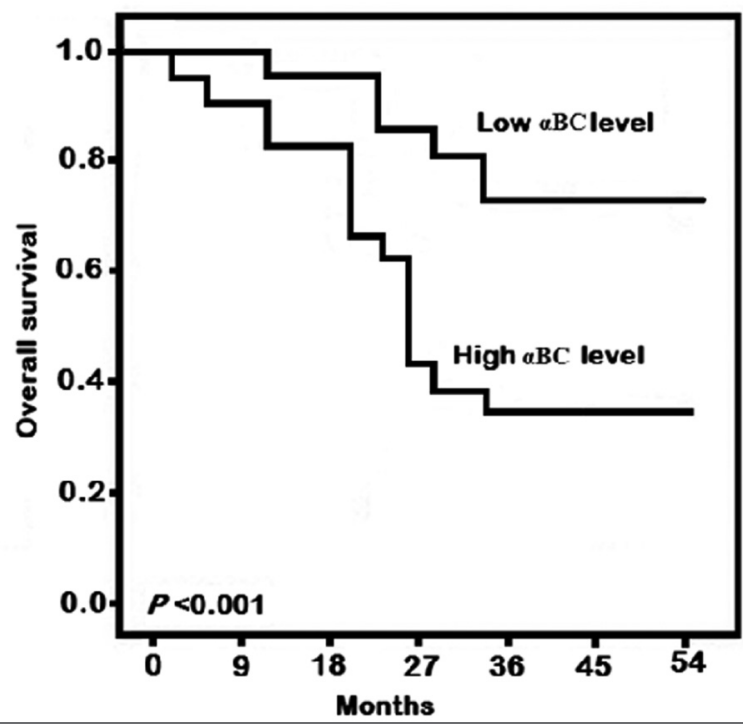

FIGURE 3. Kaplan Meier overall survival curve for patients with locally advanced laryngeal cancer as per the aBC levels
4.0 I to 9.92. The mean \pm SD level was $7.73 \pm 1.41$ SD; meanwhile, its level ranged from 0.14 to 2.41 with a mean \pm SD level was $1.29 \pm 0.57$ in the nearby normal tissues. The difference was statistically significant $p<0.00$ I. (Figure I)

The level of aBC in SCC was correlated with the characteristics of all the patients; data are presented in Table 3. There was a significant correlation with the age of patients $(p=0.003)$. The sex of the patients was not related to the aBC level. Significant correlations were observed with the size and extent of the primary tumor $(T)$, $(p<0.000 \mathrm{l})$, regional lymph node involvement $(N), p=0.0198)$, and tumor stage $(p<0.000 \mathrm{I})$. We observed that the aBC level increases with the tumor stage; detailed analyses of stage and the $\mathrm{aBC}$ levels are shown in Figure 2. Patients with T3NO tumors had a mean level of aBC of 6.43 , while those with $\mathrm{T} 4 \mathrm{~N} 2$ had a mean level of 9.53 , the difference was significant $(p<0.0001)$.

The level of $\mathrm{ABC}$ was significantly related to the tumor stage; low stage tumors had a low level of aBC level and vice versa, one-way analysis of variance, $F=22.7, p<0.0001$.

The treatment response was assessed with the level of $a B C$; the mean level of $\mathrm{ABC}$ in patients with $\mathrm{CR}$ was 6.12, while that in those with partial or no response was 7.35 with a significant difference $(p<0.0001)$, Table 3 .

At 36 mon, the patterns of failure (locoregional, or distant) in 22 patients with no response to treatment who underwent surgical resection with or without postoperative radiotherapy were as follows: 10 patients died; 7 had locoregional recurrence; 3 had distant metastases; and 2 had both, locoregional and distant relapse. In contrast, of the 32 patients who achieved CR after chemotherapy-radiotherapy, 2 died without evidence of disease because of other causes; 10 had locoregional recurrence of disease; 2 had distant metastasis; and I had both, local and distant relapse, leaving 17 patients living with laryngeal preservation.

We further explored the effect of aBC level on a patient's survival in laryngeal cancer. Our evaluation revealed that both, over-

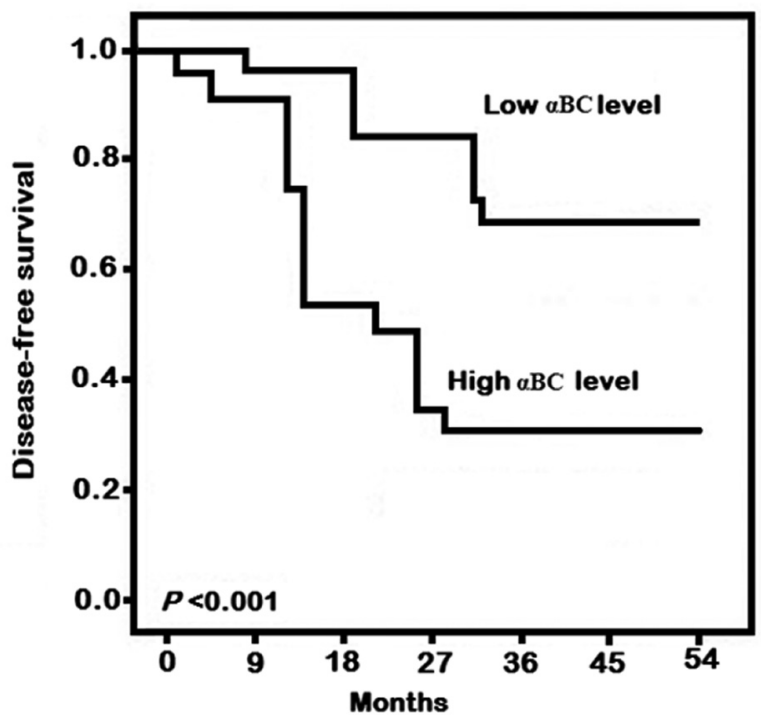

FIGURE 4. Kaplan Meier disease-free survival curve for patients with locally advanced laryngeal cancer as per the aBC levels 
all survival and disease-free survival in patients with high aBC levels were all shorter than those in patients with low aBC level. $(p<0.001$, Figure 3, 4).

The overall survival in patients with low levels of aBC was $74 \%$ versus $35 \%$ in patients with high levels of $a B C(p<0.00 I)$.

The disease-free survival in patients with low levels of aBC was $72 \%$ versus $32 \%$ in patients with high levels of $a B C(p<0.001)$.

\section{DISCUSSION}

In the treatment of head and neck cancer, two issues are most importance. The first is survival and the second is the preservation of organ function (quality of life) $(3,16,17)$. Although survival differs by the cancer site within the head and neck, it is generally poor in stages III and IV. Since the end of the 1970s, several studies have been published on induction or neoadjuvant chemotherapy in patients with head and neck cancer. Most investigators have shown that induction chemotherapy provided poor results because there was no improvement in survival or disease control. However, several studies suggest that induction chemotherapy may play an important role in preserving laryngeal function (phonatory speech) $(18,19)$. Recent data from a large number of published studies indicate that induction platinum and fluorouracil chemotherapy followed by radiotherapy can achieve laryngeal preservation in $30 \%-50 \%$ of patients, even with long-term follow-up (20-22). Furthermore, no compromise in survival was associated with the delay in surgery and radiotherapy in cases where chemotherapy failed.

Our results of a $31.5 \%$ laryngeal-preservation rate in laryngeal cancer are consistent with other studies and support further investigation of laryngeal-preservation strategies in patients with locally advanced laryngeal cancer (23-25). In order to maintain the larynx, comprehensive radiation therapy was used in selected cases, with laryngectomy intended for patients with tumor recurrence following radiation; however, the overall cure rates have been decreased (26-28). The largest studies found 3-year disease-free survival rates of $20 \%-50 \%$ for patients with advanced-stage III or IV cancers, with larynx preservation in less than half of the cured patients $(29,30)$. Geretschläger reported 3-year locoregional control (LRC), distant metastasis-free survival, and overall survival (OS) rates of $77 \%, 96 \%$, and $63 \%$, respectively (29). Our patients had more advanced disease than those reported by Geretschläger. Those patients were not eligible for radical radiation therapy with salvage surgery as this approach was associated with a low cure rates. The encouraging results achieved in these patients with advanced cancers suggest that initial chemotherapy improved the effectiveness of definitive radiation therapy (26). We believe that a shift in the clinical strategy is necessary to reduce the laryngeal cancer-related mortality. In an attempt to support this view, we studied Alpha-B-crystalline ( $\mathrm{aBC}$ ) as a possible molecular marker for predicting response to induction chemotherapy and survival in locally advanced SCC of the larynx. We examined the levels of $\mathrm{aBC}$ in SCC of the larynx and their nearby normal tissues. A significant difference was observed in its levels in SCC of the larynx and their nearby normal laryngeal tissues. We also analyzed the relation between its levels and different clinical factors. We observed that an advanced tumor stage was associated with a high aBC level. Moreover, a significant increase in its level was observed in older patients. The patient's sex was not related to the $\mathrm{aBC}$ level. Another significant observation was its relation to the response to induction chemotherapy and radiation therapy. Patients with CR had lower aBC levels than those with partial or no response.

We further evaluated the effect of aBC level on patient survival; the $O S$ and disease-free survival were shorter in patients with high $\mathrm{aBC}$ levels than in those with low aBC levels $(p<0.00 \mathrm{I})$.

Our results support the observations of Mao et al. (3I) who found that the $\mathrm{aBC}$ level was higher in laryngeal SCC than in their adjacent normal tissues and tumor stage. Contrary to our findings, their results indicated no significant relationship to patient age. Our observations also support those of Yilmaz et al. (32) who studied the aBC expression in metastatic, non-metastatic laryngeal SCC, and normal tissue samples and found a significant correlation between the level of $\mathrm{ABC}$ and laryngeal SCC, but an insignificant correlation with the tumor stage and lymph node metastases.

To the best of our knowledge, this is the first to evaluate the $\mathrm{aBC}$ levels in patients with SCC of the larynx and the response to induction chemotherapy. $\mathrm{ABC}$ is expressed in several types of malignant tumors. In ovarian cancer, Tan et al. (II). found a high $\mathrm{aBC}$ expression in the ovarian cancer tissues and its level was significantly correlated with the tumor size $(p=0.028)$, lymph node metastasis ( $p=0.000)$, distant metastasis $(p=0.005)$, tumor node metastasis stage $(p=0.002)$, and survival $(p=0.000)$. Shi et al. (33) revealed that the $\mathrm{aBC}$ levels were considerably elevated in colorectal cancer tissues as compared to that in the corresponding non-cancerous tissues ( $p<0.05$ and $p=0.014$, respectively). They also stated that this elevation was significantly related to distant metastasis $(p=0.040)$ and OS $(p=0.003)$. Chen et al. (34) found that in gastric cancer tissues, the $\mathrm{aBC}$ expression is up-regulated relative to matched ordinary tissues and is closely correlated with cancer metastasis and shorter survival time.

We conclude that while more comprehensive trials with a larger sample and longer follow-up are required to confirm these findings, induction chemotherapy can be used effectively in locally advanced laryngeal cancer followed by radiotherapy or efficient conservation of the larynx in a certain proportion of patients without compromising survival. A high aBC level may be correlated with the aggressive behavior of SCC of the larynx and unfavorable outcomes.

Ethics Committee Approval: Ethics committee approval was received for this study from the ethics committee of Zagazig University (257/2013).

\section{Informed Consent: N/A}

Peer-review: Externally peer-reviewed.

Author contributions: Concept - R.A., S.A.; Design - U.G., W.E., R.A.; Supervision - R.A., M.A., M.E.Y.; Resource - W.E., A.F.G., H.A., M.E.Y., U.G.; Materials - A.F.G., M.E.Y., U.G.; Data Collection and/or Processing - H.A., A.F.G., M.E.Y., U.G.; Analysis and/or Interpretation - A.F.G., M.A., U.G.; Literature Search - A.N.A., H.A., M.E.Y.; Writing - R.A., A.F.G., A.N.A., M.E.Y.; Critical Reviews - R.A., S.A., A.F.G., U.G.

Conflict of Interest: Authors have no conflicts of interest to declare. 
Financial Disclosure: The authors declared that this study has received no financial support.

\section{REFERENCES}

I. Sobczyk G, Kizler-Sobczyk K, Kawecki A, Krzeski A, Wółtowicz P. Total Laryngectomy with Radiotherapy in Stage T3-T4. Otolaryngol Head Neck Surg 20I2; 147(2_suppl): 185. [Crossref]

2. da Silva AP, Feliciano T, Freitas SV, Esteves S, e Sousa CA. Quality of life in patients submitted to total laryngectomy. J Voice 2015; 29(3): 382-8. [Crossref]

3. Goyal S, Pounikar T, Jain P, Arya R, Verma J. Comparison of outcome and toxicity of two different regimes of neoadjuvant chemotherapy followed by external beam radiotherapy in stages III and IV larynx and laryngopharyngeal malignancies in years 2013-20I4. J Cancer Res Ther 2016; 12(2): 920. [Crossref]

4. Burgy M, Leblanc J, Borel C. Any place left for induction chemotherapy for locally advanced head and neck squamous cell carcinoma? Anticancer Drugs 2018; 29(4): 287-94. [Crossref]

5. Yamamoto S, Yamashita A, Arakaki N, Nemoto H, Yamazaki T. Prevention of aberrant protein aggregation by anchoring the molecular chaperone aB-crystallin to the endoplasmic reticulum. Biochem Biophys Res Commun 20l4; 455(3-4): 24l-5. [Crossref]

6. Carver JA, Grosas AB, Ecroyd H, Quinlan RA. The functional roles of the unstructured $\mathrm{N}$-and $\mathrm{C}$-terminal regions in aB-crystallin and other mammalian small heat-shock proteins. Cell Stress Chaperones 2017; 22(4): 627-38. [Crossref]

7. Bakthisaran R, Akula KK, Tangirala R, Rao CM. Phosphorylation of aB-crystallin: role in stress, aging and patho-physiological conditions. Biochim Biophys Acta 2016; 1860(1): 167-82. [Crossref]

8. Kannan R, Sreekumar PG, Hinton DR. Alpha crystallins in the retinal pigment epithelium and implications for the pathogenesis and treatment of age-related macular degeneration. Biochim Biophys Acta 2016; 1860(I): 258-68. [Crossref]

9. Zhang J, Liu J, Wu J, Li W, Chen Z, Yang L. Progression of the role of CRYAB in signaling pathways and cancers. Onco Targets Ther 2019; 12: 4129-39. [Crossref]

10. Kim MS, Lee HW, Jun SY, Lee EH. Expression of alpha B crystallin and $\mathrm{BCL} 2$ in patients with infiltrating ductal carcinoma. Int $\mathrm{J}$ Clin Exp Pathol 2015; 8(8): 8842.

II. Tan L, Sha L, Hou N, Zhang M, Ma Q, Shi C. High a B-crystallin and p53 co-expression is associated with poor prognosis in ovarian cancer. Biosci Rep 2019; 39(6): BSR20182407. [Crossref]

12. Lydiatt WM, Patel SG, O'Sullivan B, Brandwein MS, Ridge JA, Migliacci JC, et al. Head and neck cancers-major changes in the American Joint Committee on cancer eighth edition cancer staging manval. CA Cancer J Clin 2017; 67(2): 122-37. [Crossref]

13. Wang JR, Habbous S, Espin-Garcia O, Chen D, Huang SH, Simpson $\mathrm{C}$, et al. Comorbidity and performance status as independent prognostic factors in patients with head and neck squamous cell carcinoma. Head Neck 2016; 38(5): 736-42. [Crossref]

14. Subbiah V, Chuang HH, Gambhire D, Kairemo K. Defining clinical response criteria and early response criteria for precision oncology: current state-of-the-art and future perspectives. Diagnostics 2017; 7(I): 10. [Crossref]

15. Ke AW, Shi GM, Zhou J, Wu FZ, Ding ZB, Hu MY, et al. Role of overexpression of $\mathrm{CDI} 5 \mathrm{I}$ and/or c-Met in predicting prognosis of hepatocellular carcinoma. Hepatology 2009; 49(2): 49I-503. [Crossref]

16. Al-Mamgani A, Navran A, Walraven I, Schreuder WH, Tesselaar ME, Klop WM. Organ-preservation (chemo) radiotherapy for T4 laryngeal and hypopharyngeal cancer: is the effort worth? Eur Arch Otorhinolaryngol 2019 Feb; 276(2): 575-83. [Crossref]

17. Goyal S, Patel PN, Gohil M, Suryanarayana U. Larynx preservation rate in laryngeal cancer patients treated with chemotherapy and radiotherapy: An institutional review of 250 patients. Acta Medica International 2016; 3(2): 14I. [Crossref]
18. Richard JM, Sancho-Garnier H, Pessey JJ, Luboinski B, Lefebvre JL, Dehesdin $D$, et al. Randomized trial of induction chemotherapy in larynx carcinoma. Oral Oncol 1998; 34(3): 224-8. [Crossref]

19. Shirinian MH, Weber RS, Lippman SM, Dimery IW, Earley CL, Garden AS, et al. Laryngeal preservation by induction chemotherapy plus radiotherapy in locally advanced head and neck cancer: the MD Anderson Cancer Center experience. Head Neck 1994; 16(I): 3944. [Crossref]

20. Argiris A, Lefebvre JL. Laryngeal preservation strategies in locally advanced laryngeal and hypopharyngeal cancers. Front Oncol 2019; 9: 419. [Crossref]

21. Patel SA, Qureshi MM, Dyer MA, Jalisi S, Grillone G, Truong MT. Comparing surgical and nonsurgical larynx-preserving treatments with total laryngectomy for locally advanced laryngeal cancer. Cancer 2019; 125(19): 3367-77. [Crossref]

22. Vilaseca I, Nogués-Sabaté A, Avilés-Jurado FX, Berenguer J, Grau $J J$, Verger $E$, et al. Factors of local recurrence and organ preservation with transoral laser microsurgery in laryngeal carcinomas; CHAID decision-tree analysis. Head Neck 2019; 4I(3): 756-64. [Crossref]

23. Dietz A, Wiegand S, Kuhnt T, Wichmann G. Laryngeal preservation approaches: considerations for new selection criteria based on the DeLOS-II trial. Front Oncol 2019; 9: 625. [Crossref]

24. Tangsriwong K, Jitreetat T. Clinical Predictors of Laryngeal Preservation Rate in Stage III-IV Laryngeal Cancer and Hypopharyngeal Cancer Patients Treated with Organ Preservation. Asian Pacific journal of cancer prevention: Asian Pac J Cancer Prev 2019; 20(7): 205I-7. [Crossref]

25. Wang Q, Liu Y, Wu K, Zhao Y, Gao C, Tong B, et al. Options of medical treatment and laryngeal function preservation in elderly patients with medial wall pyriform sinus cancer. Onco Targets Ther 2018; II: 744I-6. [Crossref]

26. Bonomi MR, Blakaj A, Blakaj D. Organ preservation for advanced larynx cancer: A review of chemotherapy and radiation combination strategies. Oral Oncol 2018; 86: 30l-6. [Crossref]

27. Kabarriti R, Brodin NP, Ahmed S, Vogelius I, Guha C, Kalnicki S, et al. Origin of Locoregional Recurrences After Definitive Intensity-modulated Radiation Therapy (IMRT) for Laryngeal Cancer Determined Based on Follow-up PET/CT Imaging. Cureus 2019; II(I): e3856. [Crossref]

28. Lu SM, Iganej S, Abdalla IA, Buchschacher GL. Concurrent Radiotherapy and Triweekly Carboplatin for the Definitive Treatment of Locally Advanced Laryngeal Carcinoma. Am J Clin Oncol 2018; 4I(6): 595-600. [Crossref]

29. Geretschläger A, Bojaxhiu B, Dal Pra A, Leiser D, Schmücking M, Arnold $A$, et al. Definitive intensity modulated radiotherapy in locally advanced hypopharygeal and laryngeal squamous cell carcinoma: mature treatment results and patterns of locoregional failure. Radiat Oncol 2015; IO(I): 20. [Crossref]

30. Wylie JP, Sen M, Swindell R, Sykes AJ, Farrington WT, Slevin NJ. Definitive radiotherapy for II 4 cases of T3NO glottic carcinoma: influence of dose-volume parameters on outcome. Radiotherapy and Oncology 1999; 53(I): 15-2I. [Crossref]

31. Mao Y, Zhang DW, Lin H, Xiong L, Liu Y, Li QD, et al. Alpha B-crystallin is a new prognostic marker for laryngeal squamous cell carcinoma. J Exp Clin Cancer Res 20I2; 3I(I): IOI. [Crossref]

32. Yilmaz M, Karatas OF, Yuceturk B, Dag H, Yener M, Ozen M. Alpha-B-crystallin expression in human laryngeal squamous cell carcinoma tissues. Head Neck 2015; 37(9): 1344-8. [Crossref]

33. Shi C, He Z, Hou N, Ni Y, Xiong L, Chen P. Alpha B-crystallin correlates with poor survival in colorectal cancer. Int J Clin Exp Pathol 2014; 7(9): 6056-63.

34. Chen D, Cao G, Qiao C, Liu G, Zhou H, Liu Q. Alpha B-crystallin promotes the invasion and metastasis of gastric cancer via NF-KBinduced epithelial-mesenchymal transition. J Cell Mol Med 20l8; 22(6): 3215-22. [Crossref] 